\title{
New Bi-Directional Mid Span Spectral Inversion Using Bi-Directional Four Wave Mixing In Semiconductor Optical Amplifiers
}

\author{
Buxens Azcoaga, Alvaro Juan; Poulsen, Henrik Nørskov; Clausen, Anders; Jepsen, Kim Stokholm; \\ Stubkjær, Kristian
}

\section{Published in:}

Proceedings of the 24th European Conference on Optical Communication

\section{Publication date:}

1998

Document Version

Publisher's PDF, also known as Version of record

Link back to DTU Orbit

Citation (APA):

Buxens Azcoaga, A. J., Poulsen, H. N., Clausen, A., Jepsen, K. S., \& Stubkjær, K. (1998). New Bi-Directional Mid Span Spectral Inversion Using Bi-Directional Four Wave Mixing In Semiconductor Optical Amplifiers. In Proceedings of the 24th European Conference on Optical Communication (Vol. Volume 3, pp. 97-99). IEEE.

\section{General rights}

Copyright and moral rights for the publications made accessible in the public portal are retained by the authors and/or other copyright owners and it is a condition of accessing publications that users recognise and abide by the legal requirements associated with these rights.

- Users may download and print one copy of any publication from the public portal for the purpose of private study or research.

- You may not further distribute the material or use it for any profit-making activity or commercial gain

- You may freely distribute the URL identifying the publication in the public portal 


\title{
New Bi-directional Mid Span Spectral Inversion using Bi-directional Four Wave Mixing in Semiconductor Optical Amplifiers
}

\author{
A. Buxens, H. N. Poulsen, A.T. Clausen, K. S. Jepsen, K. E. Stubkjaer
}

Department of Electromagnetic Systems, Building 348, Technical University of Denmark, DK-2800 Lyngby, Denmark Phone: +45 45253782, Fax: 45931634, email: aba@emi.dtu.dk

Abstract: We report bi-directional four wave mixing in a SOA. A $10 \mathrm{~Gb} / \mathrm{s} R \mathrm{RZ} 60 \mathrm{Km}$ bi-directional mid-span spectral inversion (MSSI) experiment with less than $2 d B$ penalty is reported. Further we propose a new scheme, the "Swapping MSSI", which allows improved wavelength allocation and bandwidth utilisation.

\section{Introduction}

We present for the first time to our knowledge bidirectional four wave mixing (FWM) in a semiconductor optical amplifier (SOA). FWM in SOAs is modulation format and speed transparent up to several $100 \mathrm{~Gb} / \mathrm{s}$, and is therefore a promising technique for ultra high-speed dispersion compensation [1] or optical signal processing $[2,3]$.

We characterise the quality of the bi-directional four wave mixing by performing a $10 \mathrm{~Gb} / \mathrm{s}$ bi-directional MSSI experiment over $60 \mathrm{~km}$ with $10 \mathrm{ps} \mathrm{RZ}$ pulses. The MSSI technique has previously proven its capabilities for high speed WDM transmission systems [4]. Bi-directional MSSI applied to WDM signals would be very attractive since it allows for efficient use of the transmission bandwidth [5] and for bi-directional optical networks $[6,7]$ with high speed channels.

We also present a new MSSI method, the "Swapping MSSI". The idea is to avoid the waste of bandwidth experienced with the classical MSSI scheme, which requires a spare set of wavelength channels as shown in Fig 1a. Especially for dense WDM such a waste of bandwidth is intolerable.

The swapping technique doubles the wavelength capacity in the available wavelength window by placing the pump for the phase conjugation at the center of the wavelength comb rather than at the edge, as illustrated in Fig. 1b. So, the phase conjugated FWM of $\lambda_{1}$ will appear at $\lambda_{2}$ while that of $\lambda_{2}$ appears at $\lambda_{1}$. Thereby the double number of channels can be accommodated. We verify the feasibility of the swapping MSSI in a bi-directional FWM experiment.

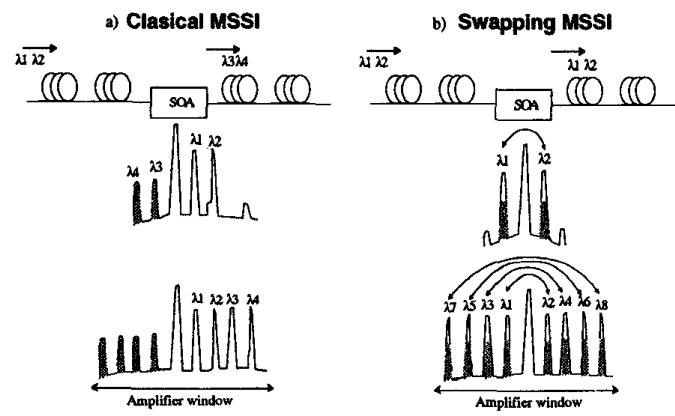

Figure 1. Schematic comparison between the a) classical and b) swapping MSSI.

\section{Bi-directional four wave mixing in a SOA}

First we demonstrate the possibility of obtaining two independent four-wave mixing products in a SOA when injecting a pump and signal simultaneously from both ends of the SOA. The quality of these four wave mixing products will be investigated in a MSSI experiment. The experimental set-up is depicted in Fig. 2. $10 \mathrm{~Gb} / \mathrm{s} \mathrm{RZ}$ signals are generated by gain-switching two DFB-lasers $\left(\lambda_{1}=1556\right.$ and $\left.\lambda_{2}=1560 \mathrm{~nm}\right)$ at $10 \mathrm{GHz}$, followed by pulse compression with DCF (10 ps pulses). External modulation is applied to the pulse train using a PRBS sequence. After transmission over $30 \mathrm{~km}$ of NDSF the signals are demultiplexed, filtered and amplified. The signals are launched from each side of the SOA together with a local $\mathrm{CW}$ pump at $\lambda_{3}=1553 \mathrm{~nm}$ inserted at both ends. Polarisation controllers, amplifiers and attenuators are used to obtain optimum polarisation state and signal levels to ensure the best FWM products. To separate incoming and out-going signals to the SOA we use circulators at both ends. The SOA is $1200 \mu \mathrm{m}$ long, based on the M-DCPBH structure and optimised for a high optical confinement factor $(\Gamma=0.6)[8]$, which improves the FWM efficiency. The filtered conjugate four wave mixing signals are combined and transmitted through another $30 \mathrm{~km}$ of NDSF. At the receiver the quality of each signal is supervised simultaneously by demultiplexing and observing the eye diagram of one signal while measuring BER curves for the other.

The simultaneous bi-directional FWM products can be observed in the spectra in Fig. 3. The average signal and

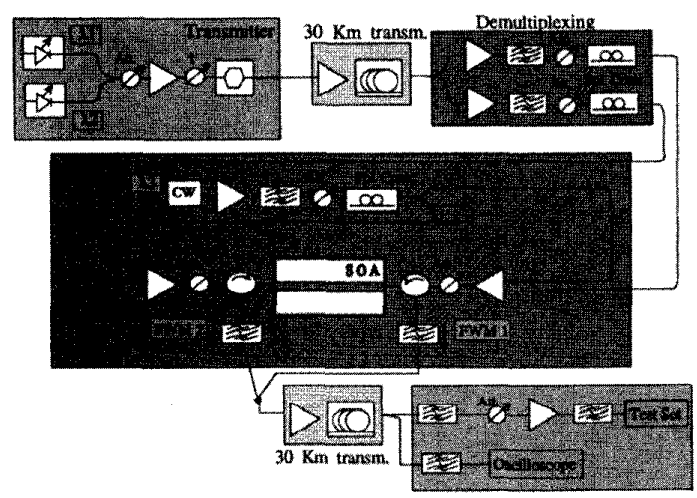

Figure 2. Experimental set-up used in the MSSI experiment. 
pump power levels coupled into the amplifier are $-4 \mathrm{dBm}$ and $9 \mathrm{dBm}$, respectively (measured in the fiber). A conversion efficiency in the order of $-18 \mathrm{~dB}$ is obtained for both signals. The optical SNR is $19 \mathrm{~dB}(0.5 \mathrm{~nm}$ resolution bandwidth) for the $1560 \mathrm{~nm}$ signal, and $17 \mathrm{~dB}$ for the 1556 $\mathrm{nm}$ signal. The peaks due to the residual power after demultiplexing can be observed.

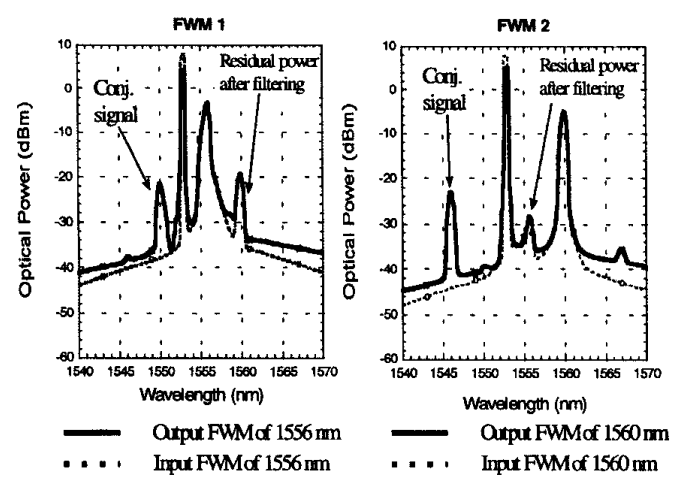

Figure 3. Simultaneous bi-directional FWM spectra.

BER measurements are presented in Fig. 4. When only one signal is transmitted the penalty induced by the MSSI is $1 \mathrm{~dB}$ for the $1556 \mathrm{~nm}$ signal and no penalty for the 1560 $\mathrm{nm}$. This difference is believed to be due to the lower SNR obtained for the 1556 signal. Less than $2 \mathrm{~dB}$ penalty is observed for simultaneous bi-directional MSSI in the SOA compared to the unidirectional MSSI case.
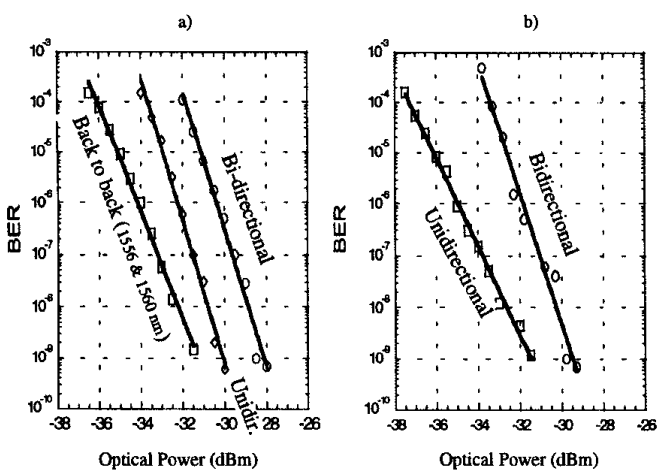

Figure 4. BER measurements for the phase conjugated signals at a) 1550 and b) $1546 \mathrm{~nm}$ in the $60 \mathrm{~km}$ MSSI experiment

\section{Swapping MSSI}

The experimental set-up used for the swapping technique is basically the same as in the bi-directional FWM. The pump wavelength is changed to $\lambda_{3}=1558 \mathrm{~nm}$ centered between $\lambda_{1}$ and $\lambda_{2}$. We increase the transmission speed at $\lambda_{1}$ to 20 $\mathrm{Gb} / \mathrm{s}$ by passive multiplexing while keeping $\lambda_{2}$ at $10 \mathrm{~Gb} / \mathrm{s}$ to measure BER.

The spectra from the swapping MSSI experiment are presented in Fig. 5. The expected asymmetric performance, due to the lower conversion efficiency towards longer wavelengths of FWM in SOAs, is avoided by independent tuning of the pump levels. A $2 \mathrm{~dB}$ difference can be observed in Fig. 5 for our experiment. Clear and open eyes can be observed for the $20 \mathrm{~Gb} / \mathrm{s}$ channel at $1560 \mathrm{~nm}$ (Fig. 6b) after $60 \mathrm{~km}$ transmission while simultaneous error free operation is achieved for the $10 \mathrm{~Gb} / \mathrm{s}$ channel at $1556 \mathrm{~nm}$ (Fig. 6c).

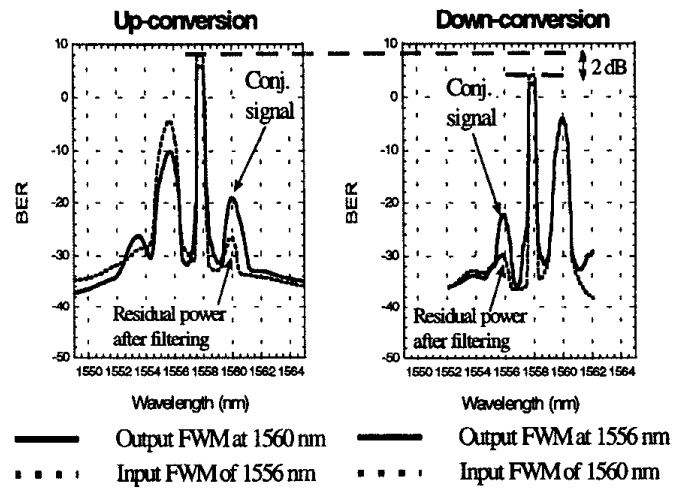

Figure 5. Simultaneous bi-directional FWM spectra from the swapping MSSI.

The residual power after filtering gives rise to coherent crosstalk in the desired phase conjugated signal. This can be eliminated by improved filtering in the demultiplexing.

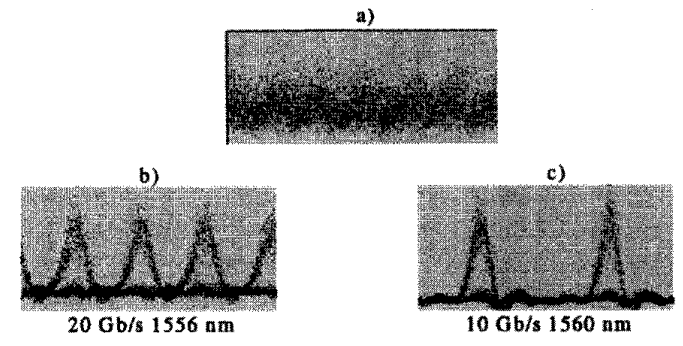

Figure 6. Eye diagrams after $60 \mathrm{~km}$. a) no MSSI. b) and c) swapping MSSI.

The proposed FWM bi-directional scheme and the swapping MSSI technique can be used at higher transmission speeds and for a larger number of channels.

\section{Conclusion}

We have demonstrated the possibility to perform simultaneous bi-directional FWM in a SOA for a $10 \mathrm{~Gb} / \mathrm{s}$ MSSI experiment over $60 \mathrm{~km}$ of fiber. The penalty when compared to single channel unidirectional FWM is less than $2 \mathrm{~dB}$ for both signals. The scheme can be upgraded to higher bit rates and number of channels, only limited by the SNR obtained in the FWM.

Further we have proposed a novel MSSI method, the swapping MSSI, which can improve the wavelength allocation and bandwidth utilisation.

\section{Acknowledgements}

This work has in part been carried out within the ACTS HIGHWAY project. France Telecom CNET and Alcatel Alsthom are acknowledged for providing devices.

References

[1] D. D Marcenac, Electron. Lett., V. 33, p. 879 (1997)

[2] T. Morioka, Electron. Lett., V. 32, p. 840 (1996)

[3] O. Kamatani, JLT, V. 14, p. 1757, (1996)

[4] S. Watanabe, ECOC'97, V. 5, p. 1 (1997)

[5] J-M P. Delavaux, ECOC`97, V. 5, p. 21 (1997)

[6] I. Yamashita, Techn. Dig. OECC'98, 15A2-3 (1998)

[7] C. H. Kim, Techn. Dig. OECC'98, PD 1-6 (1998)

[8] P. Doussiere, PTL, V. 6, p. 170 (1994) 